\title{
Dynamic tracking model for the reservoir water flooding of a separated layer water injection based on a well temperature $\log$
}

\author{
Keliu Wu Xianfang Li $\cdot$ Ming Ruan • \\ Mingyou Yu $\cdot$ Xiyao Du $\cdot$ Liangliang Jiang $\cdot$ \\ Qiu Li
}

Received: 20 March 2013/ Accepted: 14 January 2014/Published online: 2 February 2014

(C) The Author(s) 2014. This article is published with open access at Springerlink.com

\begin{abstract}
A dynamic tracking model for the reservoir water flooding of a separated layer water injection was established. Based on the basic principles of heat and mass transfer, the water profile was determined using a well temperature curve. The Poisson process analysis and stochastic process methods were applied to calculate the water saturation, water breakthrough time, and water cut of each layer in a water-flooded reservoir at any given time. When the oil reservoir was producing water, the water cut predicted by the models, with consideration of the micro-pore distribution, approximated the practical measurement, having an error of less than $5 \%$. The sample application clearly indicated that larger water injection intensity (water intake per unit thickness) could result in more drastic water saturation variation, earlier water breakthrough, and faster increase in the water cut for layers with numerous highpermeability channels, such as fractures.
\end{abstract}

Keywords Water cut - Separated layer water injection . Well temperature $\log \cdot$ Model $\cdot$ Stochastic process

\section{K. Wu $(\bowtie) \cdot$ X. Li $\cdot$ X. Du $\cdot$ Q. Li}

College of Petroleum Engineering, China University of Petroleum, 231\#, Changping District, Beijing 102249, China e-mail: wukeliu19850109@163.com; wukeliu123@gmail.com

\section{Ruan}

Xi'an Shiyou University, Xi'an 710065, China

M. Yu

The Third Drilling Company of Daqing Drilling Group, Daqing 163001, China

L. Jiang

Chemical and Petroleum Engineering, University of Calgary, Calgary, AB T2N 1N4, Canada

\section{Introduction}

For a water-flooded reservoir, water saturation, and water cut are key indices used to evaluate the reservoir water-out behavior as well as to monitor and manage the reservoir (Guo and Sun 1998; Li et al. 2011; Kazeem et al. 2007; Yang et al. 2006).

The main water saturation measurement methods include sealing core drilling (Wang et al. 2010; Guo and Lu 1996), geophysical logging (He et al. 2010), numerical reservoir simulation, and single-well chemical tracing (Deans 1971, 1974; Deans and Mut 1997; Cockin et al. 2000). Sealing core drilling is costly, and data points are limited. Geophysical logging can hardly meet the accuracy and effectiveness of production practice requirements, because this method commonly makes predictions based on logging information obtained using empirical correlation or regression techniques. For a reservoir simulation, the workload is heavy, and the computation period is long. Obtaining the water saturation by applying single-well chemical tracer tests is based on the chromatographic separation principle of the tracer in the reservoir. This test depends on the chromatographic effect in a balanced state. The test results are highly accurate, but costly.

Water-cut prediction methods primarily comprise numerical simulation, empirical correlation, and an analytical approach. Water-cut prediction is difficult and can be significantly affected by the reservoir and fluid properties as well as other factors (Guo and Sun 1998; Qu et al. 2010). Numerical simulation is a superior forecasting method, but it consumes a great deal of time (Zhao et al. 2004). Empirical correlation is a mathematical method of data processing that lacks a specific physical ground. This method includes an established water-cut prediction model using Neural Networks (Tang and Luo 2003), Usher Model 
(Yang 2008), Weibull Model, Warren Model, and Rayleigh Model (Liu et al. 2009) based on the reservoir static and production dynamic data; an established formula by fitting the plot of water cut with experimental data (Liu et al. 2011); and an established quantitatively characterized model of variations in water cut based on the actual water cut and the quantitatively characterized model principles (Zhao et al. 2010). Analytical approaches embrace the water-cut prediction method based on the water saturation function and fractional flow theory (Ershagi and Omoregie 1978; Sitorus et al. 2006; Lo et al. 1990; Ershagi and Abdassah 1984), the mathematical correlation model between the water cut and time established based on making certain assumptions for the reservoir ( $\mathrm{Li}$ et al. 2011; Kazeem et al. 2007; Jiang et al. 1999), and the analytical solution to the water cut established by calculating the complex potential and portraying flow streamlines in a flooding pattern (Xu et al. 2010). These methods are unsuitable for the prediction of the water cut for a reservoir with a separated layer water injection.

In this paper, we calculated the water saturation, water breakthrough time, and water cut of each layer at any given time based on the water injection profile derived from a well temperature curve, Poisson process analysis, and stochastic process methods. We believe that this model can provide theoretical guide for a separate layer water shutoff during the development of a water-flooded reservoir.

\section{Model establishment and solution}

Water injection profile

For a water-flooded reservoir with a separated layer water injection, the water injection profile can be determined by applying the basic principles of heat and mass transfer based on the temperature profile of the injected water and the reservoir rock in a well bore ( $\mathrm{Li}$ et al. 1999; Fagley et al. 1982), as shown in Fig. 1.

1. Heat and mass transfer equation for the water phase. Water temperature in the borehole varies as follows:

$$
\begin{aligned}
\rho_{\mathrm{w}} C_{\mathrm{w}} \frac{\partial T_{\mathrm{w}}}{\partial t}= & \rho_{\mathrm{w}} C_{\mathrm{w}} v \frac{\partial T_{\mathrm{w}}}{\partial z}+k_{\mathrm{w}} \frac{\partial^{2} T_{\mathrm{w}}}{\partial z^{2}} \\
& +\frac{2 h}{r_{\mathrm{w}}}\left[T\left(r_{\mathrm{w}}, z, t\right)-T_{\mathrm{w}}(z, t)\right],
\end{aligned}
$$

where the initial conditions are

$T_{\mathrm{w}}(z, 0)=a+b z$,

and the boundary conditions are

$T_{\mathrm{w}}\left(z_{\max }, t\right)=T_{\mathrm{s}}(t)$, where $0<t \leq t_{\mathrm{si}}$,

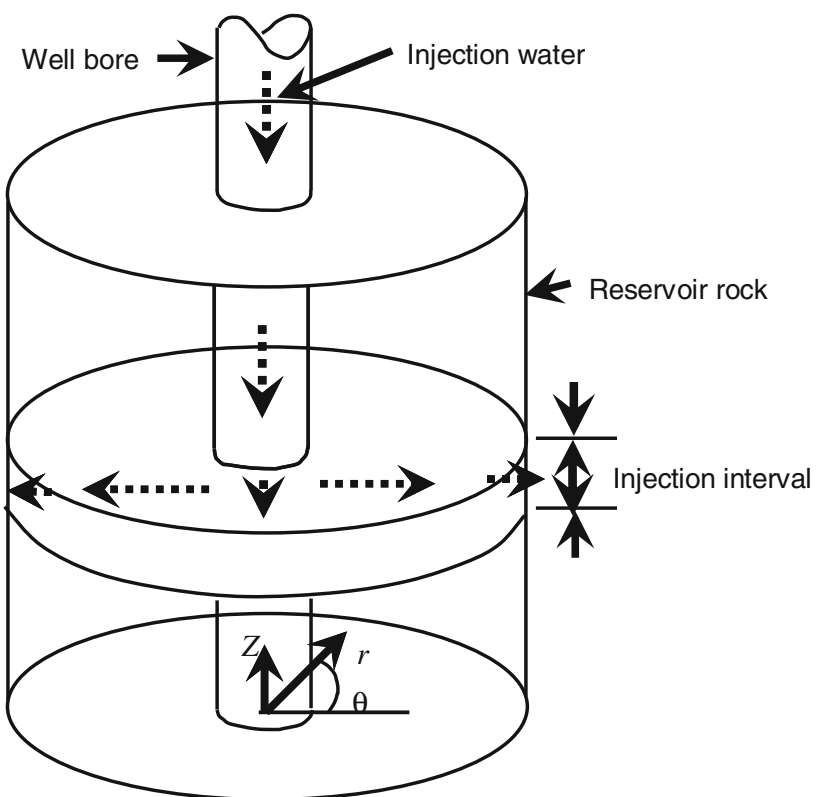

Fig. 1 Schematic diagram of mass and heat transfer in bore hole

$k_{\mathrm{w}} \frac{\partial T_{\mathrm{w}}\left(z_{\mathrm{max}}, t\right)}{\partial z}=0$, where $t_{\mathrm{si}} \leq t$,

$k_{\mathrm{w}} \frac{\partial T_{\mathrm{w}}(0, t)}{\partial z}=0$, where $0<t$,

and $h$ is

$h=\alpha\left[T\left(r_{\mathrm{in}}, z, t\right)-T_{\mathrm{w}}(z, t)\right]^{1 / 4}$.

Equation (1) describes the variation in temperature during water phase flow in a borehole. When the convection component equals zero, i.e., $\rho_{\mathrm{w}} C_{\mathrm{w}} v \frac{\partial T_{\mathrm{w}}}{\partial z}=0$, the equation also describes a well shut.

2. Heat and mass transfer equation for the reservoir rock. The reservoir temperature variation equation can be written as follows:

$$
\begin{aligned}
\rho_{\mathrm{e}} C_{\mathrm{e}} \frac{\partial T}{\partial t}= & \frac{1}{r} \frac{\partial}{\partial r}\left(r k_{\mathrm{fe}} \frac{\partial T}{\partial r}\right)+\frac{\partial}{\partial z}\left(k_{\mathrm{fe}} \frac{\partial T}{\partial z}\right)-\frac{q_{\mathrm{w}} \rho_{\mathrm{w}} C_{\mathrm{w}}}{2 \pi r} \frac{\partial T}{\partial r} \\
& +\frac{q_{\mathrm{w}}\left(p_{\mathrm{w}}-p_{\mathrm{e}}\right)}{2 \pi r^{2} J_{\mathrm{c}} \ln \left(r_{\mathrm{e}} / r_{\mathrm{w}}\right)},
\end{aligned}
$$

where the initial conditions are

$T(r, z, 0)=a+b z$,

and the boundary conditions are

$$
\begin{aligned}
& T\left(r_{\mathrm{e}}, z, t\right)=a+b z, \\
& T(r, 0, t)=a, \\
& T\left(r, z_{\max }, t\right)=a+b z_{\max },
\end{aligned}
$$

and 
$k_{\mathrm{fe}} \frac{\partial T}{\partial r}\left(r_{\mathrm{w}}, z, t\right)=h\left[T_{\mathrm{w}}(z, t)-T\left(r_{\mathrm{w}}, z, t\right)\right],\left(0 \leq z \leq z_{1}, z_{2} \leq z \leq z_{\mathrm{r}}\right.$

$T\left(r_{\mathrm{w}}, z, t\right)=T_{\mathrm{w}}(z, t),\left(z_{1}<z<z_{2}, 0<t \leq t_{\mathrm{si}}\right)$,

and $J_{c}$ is the work and thermal conversion coefficient equal to $427(\mathrm{~m} \mathrm{~kg}) / \mathrm{kJ}$.

Equation (6) describes the heat balance of the reservoir rock around the borehole as well as the water injection layer. When the radial convection and the friction heat components are equal to zero, i.e., $\frac{q_{\mathrm{w}} \rho_{\mathrm{w}} C_{\mathrm{w}}}{2 \pi r} \frac{\partial T}{\partial r}=0$ and $\frac{q_{\mathrm{w}}\left(p_{\mathrm{w}}-p_{\mathrm{e}}\right)}{2 \pi r^{2} J_{\mathrm{c}} \ln \left(r_{\mathrm{e}} / r_{\mathrm{w}}\right)}=0$, respectively, the equation is also applicable to the un-injection layers and water injection layers after a well shut.

The water injection volume for each layer at any given time $q_{\mathrm{w}}(1, j, t)$ can be obtained by computing the finite difference between Eqs. (1) and (6) with the initial and boundary conditions as follows: First, given an initial injection water profile $q_{\mathrm{w}}\left(1, j, t_{0}\right)$, the numerical solution $T_{1, j}^{t}$ is calculated, the numerical solution and the actual well temperature are compared, and then the water injection profile $q_{\mathrm{w}}(1, j, t)$ is adjusted to approximate the numerical solution $T_{1, j}^{t}$ to the actual well temperature. The numerical solution $q_{\mathrm{w}}(1, j, t)$ can be regarded as the actual injection water volume at time $t$, where $q_{\mathrm{w}}(1, j, t)$ is the water injection volume of the first radial grid and the $j^{\text {th }}$ vertical grid at time $t$, and $T_{1, j}^{t}$ is the well temperature of the first radial grid and the $j$ th vertical grid at time $t$.

\section{Water streamlines the velocity}

Generally, the advancing velocity of the injected water is closely related to the pore structure of the water-flooded reservoir. In a water/oil displacement experiment, we commonly use $\varphi$ to denote the core porosity, $A$ to denote the cross section area, $Q$ to denote the water injection rate, $\mathrm{d} p / \mathrm{d} l$ to denote the pressure gradient, and $Q / \varphi$ to denote the water-flooded core volume per unit time. Then, the advancing velocity of the injected water in the core is $Q /$ $(A \varphi)$ (Fig. 2).

Assuming that the core pore diameter distribution is divided into $N$ levels: $\gamma_{1}, \gamma_{2}, \ldots, \gamma_{N}$, with each proportion $p\left(\gamma_{j}\right)=p_{j}$, where $j=1,2 \ldots, N ; p_{1}+p_{2}+\cdots+p_{\mathrm{N}}=1$. If the number of pores in $\lambda_{j}$ passed by a line parallel to the core axis satisfying the Poisson process (Yao et al. 1999), i.e., for a core length $L$, assuming that the number of pores with length $l(0 \leq l \leq L)$ passing through the diameter $\gamma_{j}$ is a random variable parameter $\zeta_{j}(l)$ with the following probability distribution:

$P\left(\zeta_{j}(l)=k\right)=\frac{\left(\lambda_{j} l\right)^{k}}{k !} e^{\lambda_{j} l}, \quad k=0,1,2, \ldots,$.

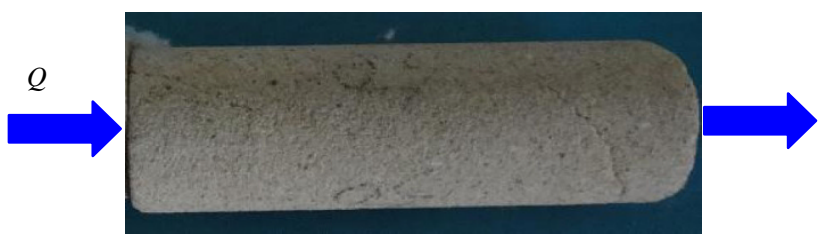

Fig. 2 The core of water/oil displacement experiment

The total number of pores that passes through all levels with diameter of length $l$ follows a random variable parameter $\eta(l)=\sum_{j=1}^{N} \zeta_{j}(l)$. According to Poisson's reproducibility, $\eta(l)$ also satisfies the Poisson process of strength $\lambda=\sum_{j=1}^{N} \lambda_{j}$, and the probability distribution is

$$
\begin{aligned}
P(\eta(l)=k) & =\frac{(\lambda l)^{k}}{k !} e^{\lambda l} \\
& =\frac{\left[\left(\lambda_{1}+\lambda_{2}+\cdots \lambda_{N}\right) l\right]^{k}}{k !} e^{\left(\lambda_{1}+\lambda_{2}+\cdots \lambda_{N}\right) l}, k \\
& =0,1,2, \ldots,
\end{aligned}
$$

The strength $\lambda$ is the average total number of pores passed by any unit length straight line parallel to the core axis. $\lambda$ can be obtained by observing and counting the slabbed core or the scanning electron microscopy images, and can also be determined by a mathematical derivation.

$\tau=l_{\text {pore }} / L=\sqrt[3]{\phi}$

where $\tau$ is the linear porosity, and $l_{\text {pore }}$ is the total length of the pores in the core.

The average diameter of the pore is

$\gamma=\sum_{j=1}^{N} \gamma_{j} P_{j}$

The average number of pore passed by the unit length is

$\lambda=\tau / \gamma=\sqrt[3]{\phi} / \gamma$

The average number of water-flooded pores in the water/ oil displacement experiment in terms of unit time is

$n=\lambda \cdot \frac{Q}{A \phi}$

The average distance $l$ connected by these pores is

$l=n \cdot \gamma=\frac{\lambda Q \gamma}{A \phi}$

The average advancing velocity of the water in the core can be expressed as

$\bar{v}=\frac{\lambda Q \gamma /(A \phi)}{\phi^{1 / 3}}=\frac{\lambda Q \gamma}{A \phi^{4 / 3}}$.

In an actual reservoir, the water advancing velocity along the water streamline is not always $v$, but a random 
variable parameter $U_{\mathrm{w}}$. Similarly, the total number of water-flooded pores along the water streamline in terms of unit time is also a random variable parameter, denoted by $\zeta_{\mathrm{w}}$, that follows the Poisson distribution

$P\left(\zeta_{\mathrm{w}}=k\right)=\frac{[\lambda Q /(A \phi)]^{k}}{k !} e^{\lambda Q /(A \phi)}, k=0,1,2, \ldots,$,

and

$U_{\mathrm{w}}=\zeta_{\mathrm{w}} \frac{\gamma}{\sqrt[3]{\phi}}$.

The Poisson distribution of $U_{\mathrm{w}}$ is

$P\left(U_{\mathrm{w}}=k \frac{\gamma}{\sqrt[3]{\phi}}\right)=\frac{[\lambda Q /(A \phi)]^{k}}{k !} e^{-\lambda Q /(A \phi)}$,

$k=0,1,2, \ldots,$.

Equations (20) and (21) describe the random advancing velocity of the water throughout the core, and the average velocity is

$$
\begin{aligned}
E\left(U_{\mathrm{w}}\right) & =\sum_{k=0}^{\infty} k \frac{\gamma}{\sqrt[3]{\phi}} P\left(U_{\mathrm{w}}=k \frac{\gamma}{\sqrt[3]{\phi}}\right)=\frac{\gamma}{\sqrt[3]{\phi}} \frac{\lambda Q \gamma}{A \phi}=\frac{\lambda Q \gamma}{A Q^{4}} \\
& =\frac{Q}{A \phi}
\end{aligned}
$$

This result is consistent with the derivation result of the water macro-advancing velocity $Q /(A \varphi)$ during the water/ oil displacement experiment. The corresponding variance is

$D\left(U_{\mathrm{w}}\right)=\frac{\gamma^{2}}{\phi^{\frac{2}{3}}} \frac{\lambda Q}{A \phi}=\frac{\lambda Q \gamma^{2}}{A \phi^{\frac{5}{3}}}$.

Assuming that $Y$ is the sum of the total number of pores that any straight line $l$ parallel to the core axis passed through, the core and the length of one side of the core, which is random variable parameter, exhibit expectation $E(Y)$ and variance $D(Y) . Y$ is a random variable parameter. $Y_{i}$ is the sum of the lengths of the pore $i$ in the water streamline and its unilateral rock. $Y_{i}$ and $Y$ are independent and have the same distribution; thus, the water advancing velocity $U_{\mathrm{w}}$ can be expressed as

$U_{\mathrm{w}}=\sum_{i=1}^{\left[\frac{\lambda Q}{A \phi}\right]} Y_{i}$.

The average value of $U_{\mathrm{w}}$ is

$E\left(U_{\mathrm{w}}\right)=\frac{\lambda Q}{A \phi} E(Y)$.

The corresponding variance is

$D\left(U_{\mathrm{w}}\right)=\frac{\lambda Q}{A \phi} D(Y)$.
The water-flooded distance within any given time period $t$ is

$U(t)=\sum_{i=1}^{\left[\frac{\lambda Q}{A \phi} t\right]} Y_{i}$,

where $\left[\frac{\lambda Q}{A \phi}\right]$ and $\left[\frac{\lambda Q}{A \phi} t\right]$ are the closest integer to $\frac{\lambda Q}{A \phi}$ and $\frac{\lambda Q}{A \phi} t$, respectively.

The average value of $U(t)$ is

$E[U(t)]=\frac{\lambda Q}{A \phi} \cdot t \cdot E(Y)$.

The corresponding variance is

$D[U(t)]=\frac{\lambda Q}{A \phi} \cdot t \cdot D(Y)$.

Water saturation

Figure 3 shows the water advancing process from the injection well to the production well for a high horizontal homogeneity reservoir developed by a five-spot waterflooding pattern. The coordinate system $0, x, y$ was established. Given its symmetry, only the triangle area below the diagonal line OB had to be analyzed

$y=x^{\alpha},(0 \leq x \leq 1, \alpha \geq 1)$,

$\operatorname{arctg} \frac{y}{x-a}-\operatorname{arctg} \frac{y}{x+a}=c$,

where $c$ is constant.

The function family curves of Eq. (30) and the streamline of Eq. (31) are similar; thus, the streamline in the triangle area can be approximated by the function $y=x^{\alpha}$. When $\alpha=1, y$ is a square diagonal of length $\sqrt{2}$; when $\alpha \rightarrow \infty, y$ is two right-angle sides of length 2 . For any value of $\alpha$, the corresponding streamline length is

$l_{\alpha}=\int_{0}^{1} \sqrt{1+\left[\frac{\mathrm{d} x^{a}}{\mathrm{~d} x}\right]} \mathrm{d} x=\int_{0}^{1} \sqrt{1+\alpha^{2} x^{2(\alpha-1)} \mathrm{d} x}$.

Selecting a batch of $\alpha$ values, where $\alpha_{1}>\alpha_{2}>\cdots>\alpha_{n}$, the $n$ strips of the streamlines can be drawn.

$y=x^{\alpha_{i}}, \quad i=1,2, \ldots, n$.

When the injection pressure $P_{\mathrm{e}}$ and the bottom hole producing pressure $P_{\mathrm{w}}$ are stable, the pressure gradient of the injected water flowing along the streamline $l_{\alpha}$ is

$\operatorname{grad} P_{\alpha}=\frac{P_{\mathrm{e}}-P_{\mathrm{w}}}{l_{\alpha}}$.

Using Darcy's law,

$Q=A \frac{K}{\mu} \operatorname{grad} P$. 
Fig. 3 Schematic diagram of water streamline in five-spot water-flooding patterns

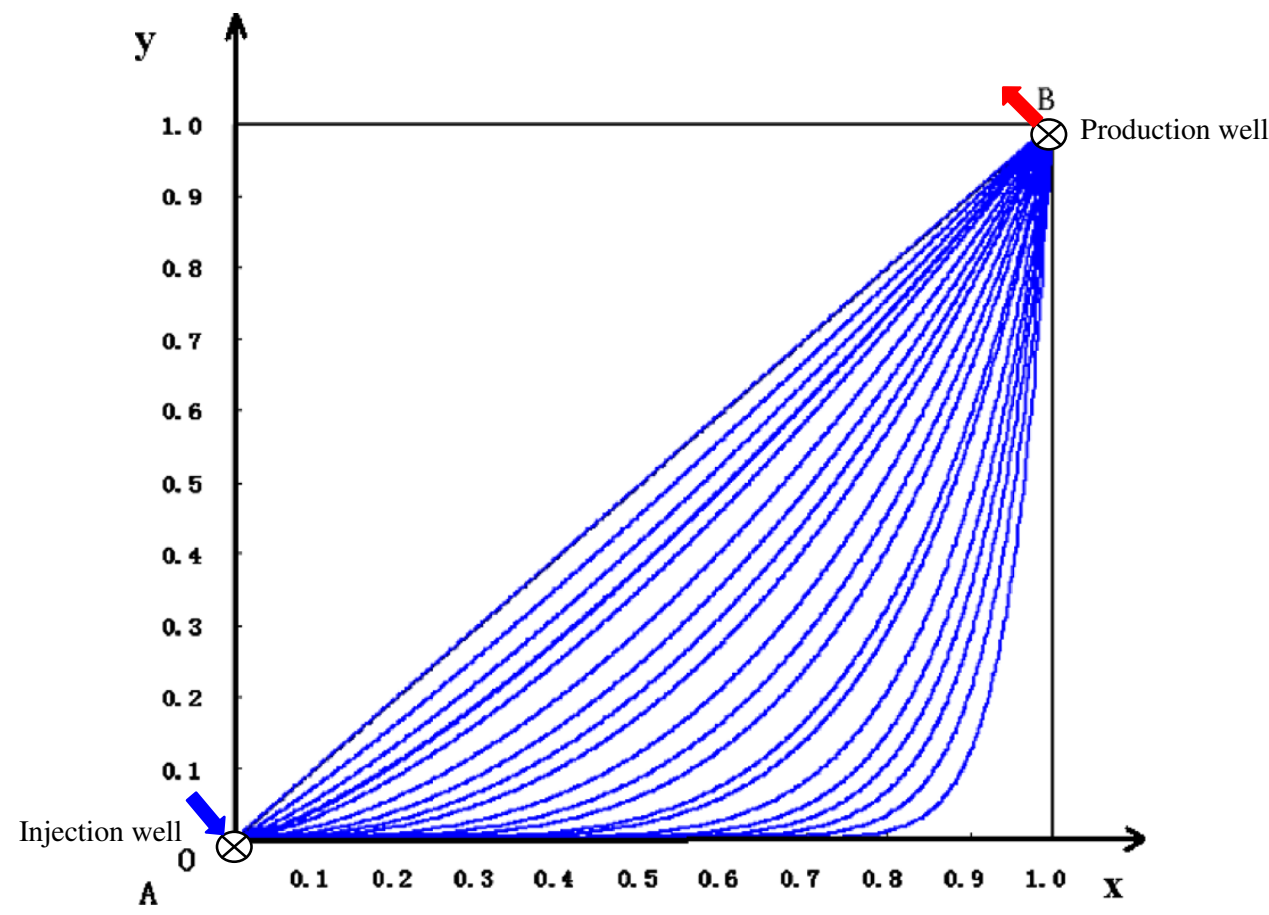

Substituting Eq. (35) into Eq. (28), the average waterflooded distance after time period $t$ is

$E[U(t)]=\frac{\lambda K t}{\mu \phi} E(Y) \cdot \operatorname{grad} P$.

Similarly, the corresponding variance of the waterflooded distance is

$D[U(t)]=\frac{\lambda K t}{\mu \phi} D(Y) \cdot \operatorname{grad} P$.

The water-flooded distance and the corresponding variance of the different streamlines at any given time can be calculated using Eqs. (36) and (37); thus, the waterflooded front of the different streamlines can be obtained at time $t$. Then, the oil-aqueous interface can be drawn by connecting the water-flooded front successively. Water saturation refers to the ratio of the area surrounded by the oil aqueous interface to the total area at time $t$.

\section{Water cut}

For the same layer, according to Darcy's law, the flux rate is directly proportional to the pressure gradient. The sum of the pressure gradient of each streamline is $\Delta P_{k}$ and is denoted as

$\Delta P_{k}=\sum_{i=1}^{n_{k}} \operatorname{grad} P_{k} \alpha_{i}$,

where $k$ is the layer number, $n_{k}$ is the total number of streamlines in layer $k$, and $\operatorname{grad} P_{k} \alpha_{i}$ is the total pressure drop of streamline $\alpha_{i}$.
Supposing that $n(t)$ strips of the streamlines reached the well bore of the production well at time $t$, and these streamlines are in the water phase, The sum of the pressure gradients of these streamlines is

$\Delta P_{k w}=\sum_{i=1}^{n_{k}(t)} \operatorname{grad} P_{k} \alpha_{i}$

Then, the water cut $f_{k w}(t)$ of layer $k$ is

$f_{k w}(t)=100 \% \cdot \frac{\Delta P_{k w}}{\Delta P_{k}}$

Calculating the water cut by applying the weighted average based on the production rate of each layer, the water cut of the production well at time $t$ is

$f_{w}(t)=\sum_{i=1}^{k} q_{k} \cdot f_{k w}(t) / Q_{L}$,

where $q_{k}$ is the liquid production rate of layer $k$, and $Q_{L}$ is the total liquid production rate of the production well.

\section{Model application}

A relatively homogeneous reservoir was developed using a five-spot water-flooding pattern. The important parameters were as follows: well depth of $3,980 \mathrm{~m}$, dominating radius of $88 \mathrm{~m}$, initial reservoir pressure, $P_{\mathrm{i}}$, of $40.8 \mathrm{MPa}$, casing pressure of $43.2 \mathrm{MPa}$, casing diameter of $14.6 \mathrm{~cm}$, well spacing of $200 \mathrm{~m}$, injection pressure, $P_{\mathrm{e}}$, of $45 \mathrm{MPa}$, water injection rate of $150 \mathrm{~m}^{3}$, injection time of $5610 \mathrm{~h}$, and 
Table 1 Distribution of reservoir pore system

\begin{tabular}{llllll}
\hline Pore diameter $(\mu \mathrm{m})$ & $>45.2$ & $45.2-30.5$ & $30.5-10.7$ & $10.7-1.1$ & $<1.1$ \\
Portion $(\%)$ & 11.2 & 23.5 & 11.7 & 7.4 & 46.2 \\
\hline
\end{tabular}

injected water temperature of $18.5^{\circ} \mathrm{C}$. The water injection layers were as follows: $L_{1}$ at $3,562.3-3,609.6 \mathrm{~m}, L_{2}$ at $3,609.6-3,668.1 \mathrm{~m}, \quad L_{3}$ at $3,668.1-3,726.6 \mathrm{~m}, \quad L_{4}$ at 3,726.6-3,785.2 m, and $L_{5}$ at 3,785.2-3,852.2 m. Furthermore, the injection water viscosity $\mu_{\mathrm{w}}$ was $1 \mathrm{mPa}$, the crude oil viscosity $\mu_{\mathrm{o}}$ was $1.5 \mathrm{mPa}$ s, the initial oil saturation $S_{\text {oi }}$ was 0.7 , the average porosity $\varphi$ was $11.25 \%$, and the permeability $K$ was $32.51 \times 10^{-3} \mu \mathrm{m}^{3}$. The distribution of the reservoir pore system is shown in Table 1 .

Determining the water injection profile

In "Water injection profile", the heat and mass transfer equations of the injection water and reservoir rock were applied to determine the water injection profile, as shown in Fig. 4.

The injecting water had five layers. First, the initial injection water profiles of these layers were as follows: $Q_{1}=19 \mathrm{~m}^{3}$, $Q_{2}=32 \mathrm{~m}^{3}, Q_{3}=30 \mathrm{~m}^{3}, Q_{4}=37 \mathrm{~m}^{3}$, and $Q_{5}=32 \mathrm{~m}^{3}$. The numerical solution $T$ (red line in Fig. 4) was calculated. This solution differs from the actual well temperature (black line in Fig. 4). The water injection profile was then adjusted to obtain the new numerical solution $T$. The new water injection profiles were $Q_{1}=24 \mathrm{~m}^{3}, Q_{2}=28 \mathrm{~m}^{3}, Q_{3}=35 \mathrm{~m}^{3}$, $Q_{4}=32 \mathrm{~m}^{3}$, and $Q_{5}=31 \mathrm{~m}^{3}$. The new numerical solution $T$ is closer to the actual well temperature (blue line in Fig. 4).

\section{Calculating the water saturation}

Based on the water streamline velocity derivation in "Water streamlines the velocity", the water advancing

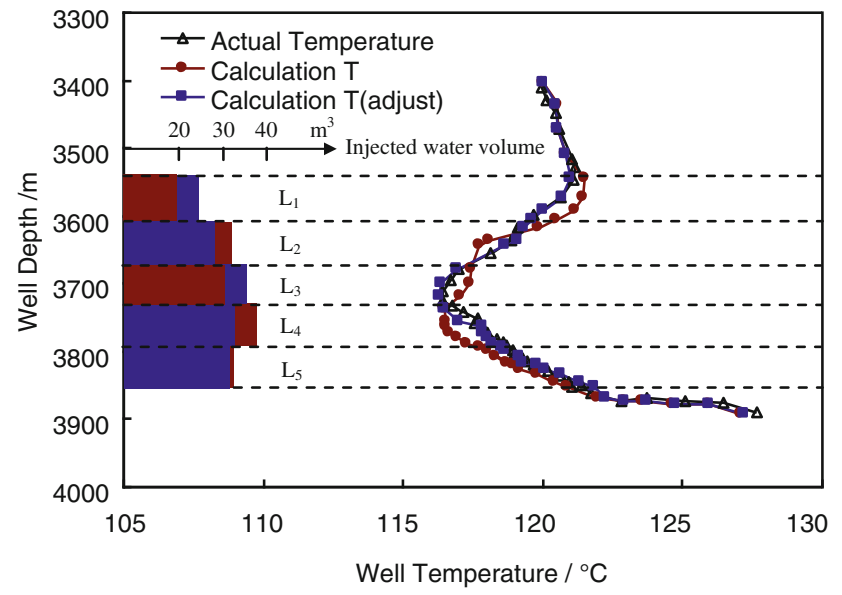

Fig. 4 Well temperature and water injection profiles of injection well distance of the different streamlines at any time based on the determined layer water injection rates in "Determining the water injection profile" were calculated. The oil water interface at any given time was determined, and the water saturation of each layer was obtained, as shown in Figs. 5, $6,7$.

Figure 5 shows that the water saturation in $L_{3}$ increased the fastest because of its maximum water intake per unit thickness of $0.648 \mathrm{~m}^{3} /(\mathrm{d} \mathrm{m})$, followed by $L_{4}$. $L_{1}$ increased the slowest because its water intake per unit thickness was $0.508 \mathrm{~m}^{3} /(\mathrm{d} \mathrm{m})$.

Figure 6 shows that the oil water interface of $L_{1}$ constantly expanded during the water-flooding development. The water breakthrough did not occur at the producers until the 1100th day.

Figure 7 shows that at the 600th day, the oil-water interface advanced the fastest in $L_{3}$ and the slowest in $L_{1}$. This result is consistent with Fig. 5.

Calculating the water cut

Based on the calculated results, the water breakthrough time and the water cut of each layer at any given time were calculated according to "Water cut", as shown in Figs. 8, $9,10$.

The layer with the smallest water breakthrough time of 779 days was $L_{3}$, in which the water cut also increased the fastest. $L_{4}$ was second, with a water breakthrough time of 884 days. The water breakthrough time of $L_{1}$ was the longest at 1,078 days, corresponding to its water cut that grew the slowest. After 1,600 days, the water cuts of all the layers were up by $80 \%$.

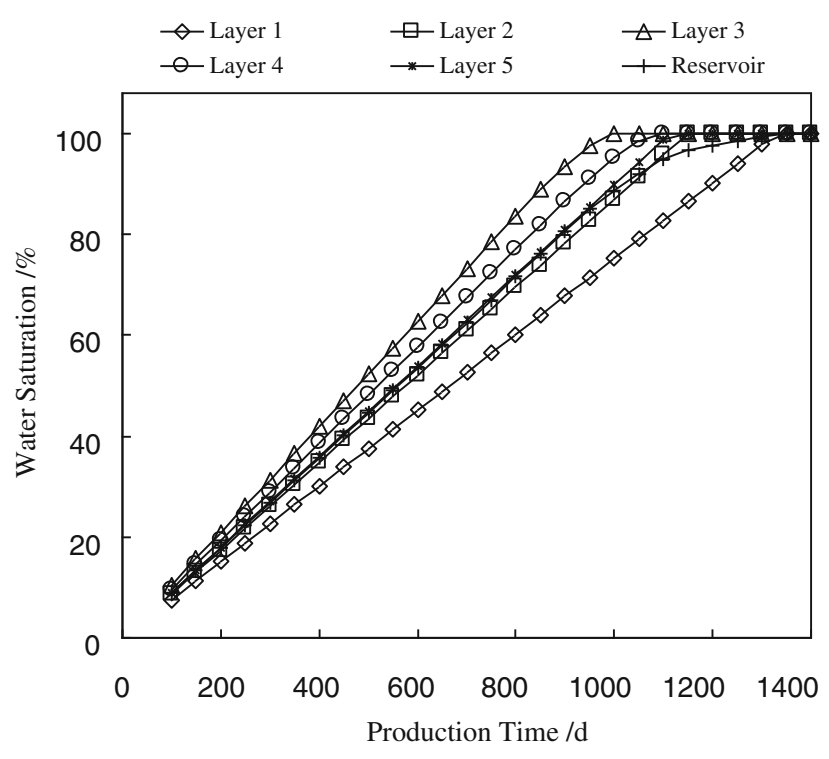

Fig. 5 Water saturation curves of each layer 
Fig. 6 The development process of oil-water interface of L1 (a)

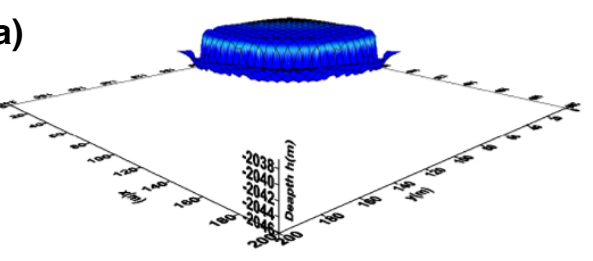

$$
300^{\text {th }} \text { day }
$$

(c)

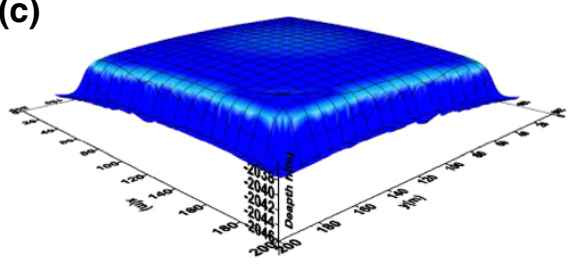

$700^{\text {th }}$ day

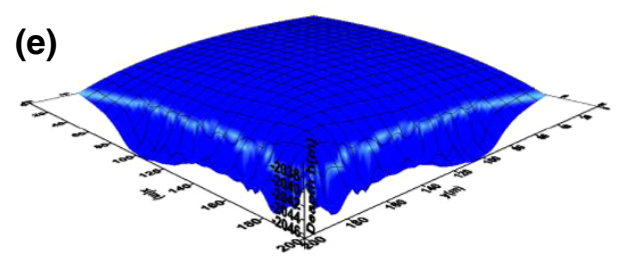

$1100^{\text {th }}$ day

Fig. 7 The oil-water interface of each layer at the 600th day (b)

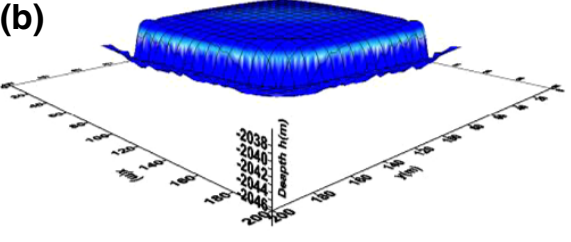

$500^{\text {th }}$ day

(d)

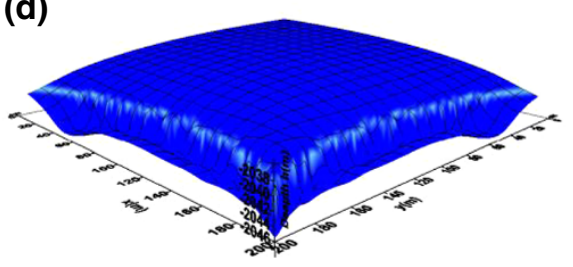

$900^{\text {th }}$ day

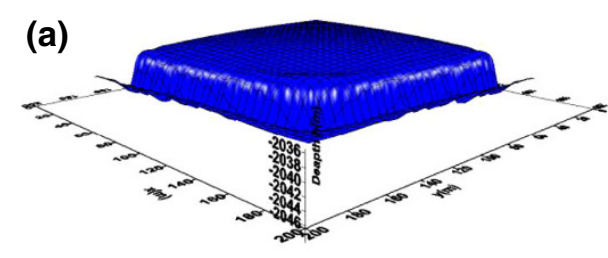

Layer 1

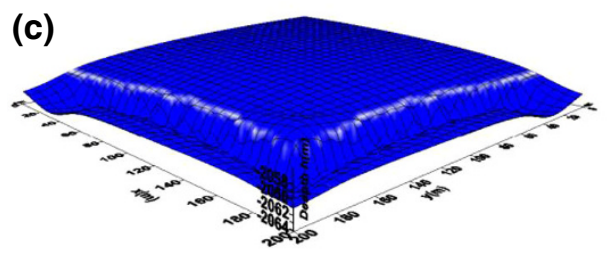

Layer 3

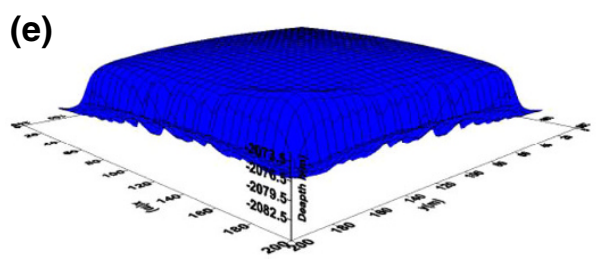

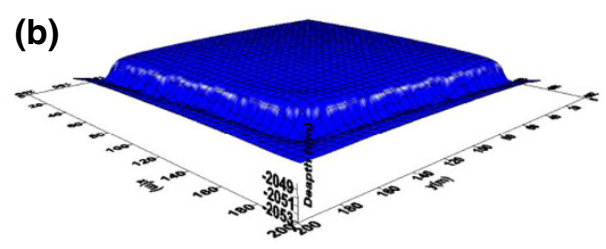

Layer 2

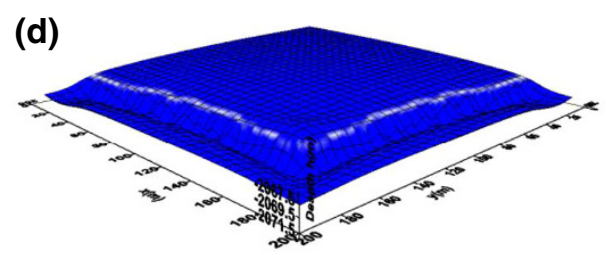

Layer 4

Layer 5 
After the water breakthrough, the water cut grew rapidly in the early stages, but then slowed down. The water cut in $L_{3}$ increased early and rose fast; its water cut was up by $98.5 \%$ at the 1250th day, which was considered as severely water flooded. Comparatively, the water cut in $\mathrm{L}_{1}$ increased late and rose slowly; its water cut exceeded $99.1 \%$ at the 1850th day, which was almost completely water flooded.

The water cuts of the producers were calculated by applying the weighted average based on the production rate of each layer. The comparison results between the calculated water cut and the actual water cut are shown in Fig. 10. The initial calculations have a larger error than the later calculations. The later calculations have an error of less than $5 \%$. This result is attributed to the fact that water mostly comes from high-permeability channels, such as cracks, during the

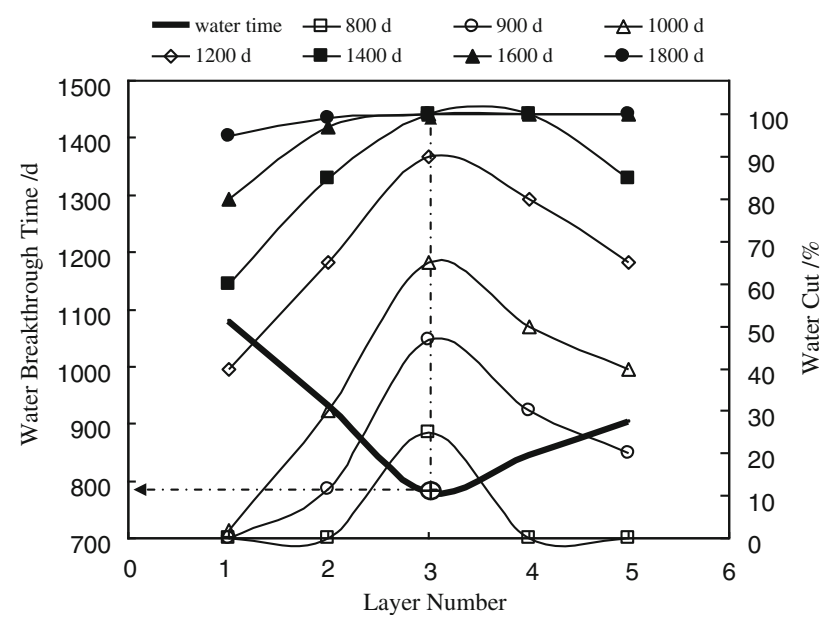

Fig. 8 Water breakthrough time and water-cut variation for each layer

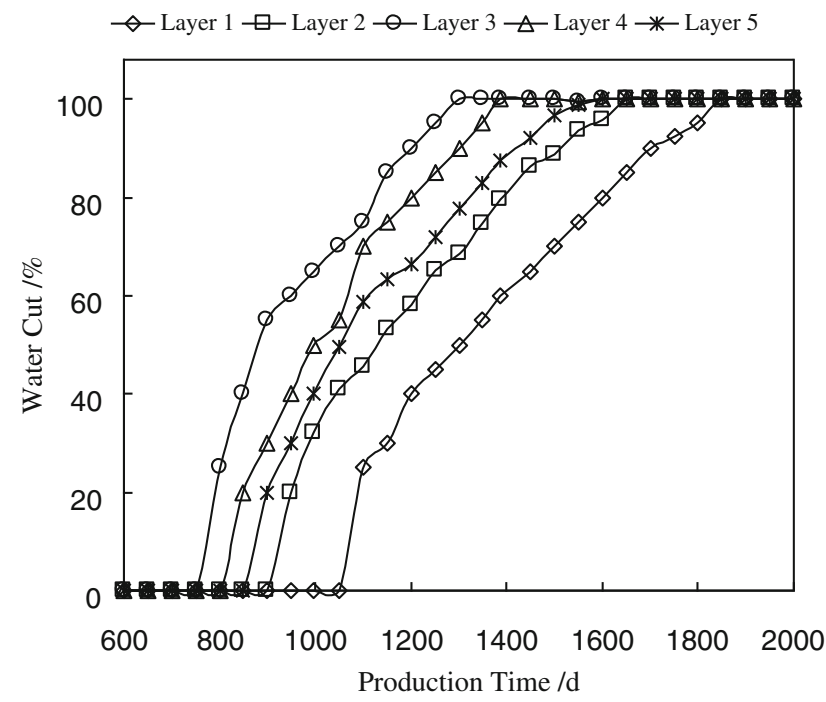

Fig. 9 Water-cut variation of each layer

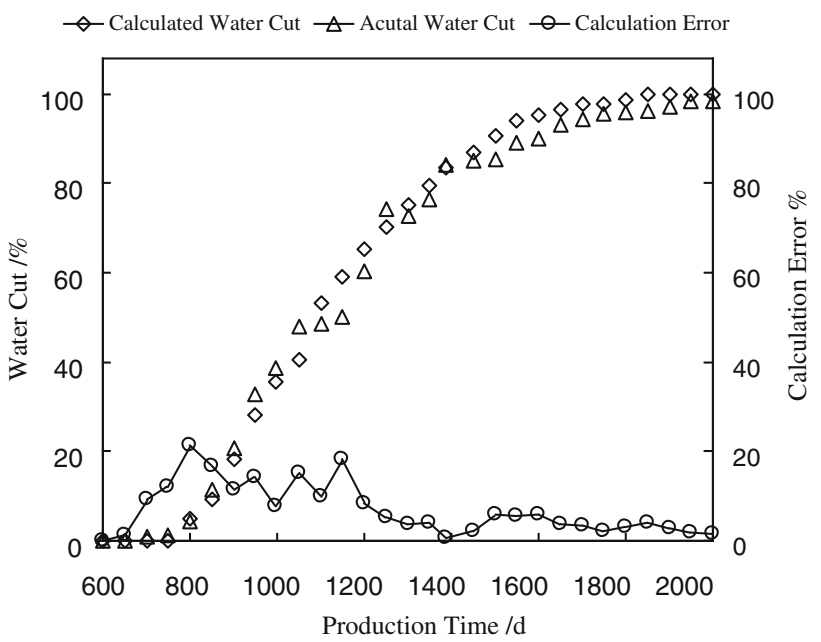

Fig. 10 Variation curve of water cut for production well

early breakthrough time, but the established model does not consider this effect. However, this effect is weakened when a water breakthrough gradually occurs in most of the layers, causing the calculated water cut to approximate the actual values; thus, the error decreases.

\section{Conclusion}

1. A dynamic tracking model for reservoir water flooding with a separated layer water injection is established. Based on the basic principles of heat and mass transfer, a well temperature curve was applied to determine the water injection profile. The Poisson process analysis and the stochastic process methods were applied to calculate the water saturation, water breakthrough time, and water cut of each layer in the water-flooded reservoir at any given time.

2. The dynamic watering out processes of each layer differ for a water-flooded reservoir with a separated layer water injection. A higher water intake for a layer per unit thickness with high flow channels, where water saturation increases faster results in a shorter water breakthrough time and faster increase in water cut, and vice versa.

3. The model prediction accuracy may vary at different development stages. For models that only consider the micro-pore distribution in a reservoir but not the high-penetration channels, such as micro-cracks, the water-cut calculation error is larger when the water mainly comes from a high-permeability channel at an early time. When the reservoir gradually becomes water flooded, the calculated water cut approximates the actual value, and the calculation error becomes less than $5 \%$. 
Acknowledgments This paper was sponsored by the National Science and Technology major project (2011ZX05030-005-04), the National Natural Science Foundation Project (50974128), and the Key Laboratory for Petroleum Engineering of the Ministry of Education (MOE) in China University of Petroleum Foundation. We recognize the support of the MOE Key Laboratory of Petroleum Engineering in the China University of Petroleum (Beijing) for the permission to publish this paper.

Open Access This article is distributed under the terms of the Creative Commons Attribution License which permits any use, distribution, and reproduction in any medium, provided the original author(s) and the source are credited.

\section{References}

Cockin AP, Malcolm LT, Mcguire PL (2000) Analysis of a singlewell chemical tracer test to measure the residual oil saturation to a hydrocarbon miscible gas flood at Prudhoe Bay. SPE Reserv Eval Eng 3(6):544-551

Deans HA (1971) Method of determining fluid saturations in reservoirs. US, PATENT: 3623842, 1971-11-30

Deans HA, Mut AD (1997) Chemical tracer studies to determine water saturation at Prudhoe Bay. SPE ReservEng 12(1):52-57

Deans HA, Shallenberger LK (1974) Single-well chemical tracer method to measure connate water saturation. In: Paper SPE 4755 presented at SPE improved oil recovery symposium, Tulsa, Oklahoma, 22-24 April. doi:10.2118/4755-MS

Ershagi I, Abdassah D (1984) A prediction technique for immiscible processes using field performance data. JPT 36(4):664-670

Ershagi I, Omoregie O (1978) A method for extrapolation of cut vs. recovery curves. JPT 30(2):203-204

Guo YL, Lu GM (1996) Regional linear model of water cut vs. water saturation in watered-out zone and its application. Oil Gas Recov Technol 3(2):45-49

Guo YL, Sun GY (1998) An analysis of factors affecting the precision of $\log$ interpretation of water cut in a watered out reservoir. Pet Explor Dev 25(4):59-61

He GF, Yuan HL, Lu T (2010) An inversion method to determine formation water resistivity and water saturations simultaneously. World Well Logging Technol 175:37-42

Jiang M, Song FX, Wu XC (1999) Building and application of a mathematical model for water cut and time relationship. Pet Explor Dev 26(1):65-67

John F, Scott FH (1982) An improved simulation for interpreting temperature logs in water injection wells. SPE J 22(5):709-718

Kazeem A, Lawal Emmanuel U, Kare L (2007) A didactic analysis of water cut trend during exponential oil-decline. In: Paper SPE 111920 presented at Nigeria annual international conference and exhibition, Abuja, Nigeria, 6-8 August. doi:10.2118/111920-MS
Li H, Zhu D, Lake LW (1999) A new method to interpret two-phase profiles from temperature and flow meter logs. In: Paper SPE 56793 presented at annual technical conference and exhibition, Houston, Texas, 3-6 October. doi:10.2118/56793-MS

Li KW, Ren XH, Li L, Fan XD (2011) A new model for predicting water cut in oil reservoirs. In: Paper SPE 143481 presented at the SPE EUROPEC/EAGE annual conference and exhibition, Vienna, Austria, 23-26 May. doi:10.2118/143481-MS

Liu ZX, Han D, Wang Q (2009) A new model for water-cut prediction in polymer flooding. Acta Petrolei Sinica 30(6): 903-907

Liu JY, Wang DS, Liu BL (2011) Study on the variation law of the water-cut of low-permeability low-saturation sandstone reservoirs in water displacing oil. J Xi an Shiyou Univ (Natural Science Edition) 26(1):37-41

Lo KK, Warner HR, Johnson JB (1990) A study of the postbreakthrough characteristics of water floods. In: Paper SPE 20064 presented at SPE California regional meeting, Ventura, California, 4-6 April. doi:10.2118/20064-MS

Qu YG, Liu YT, Xu XW (2010) Influential factors of water-cut variation in multi-layer and complicated fault-block reservoirs in Gaoshangbao Oilfield. J Oil Gas Technol 32(2):120-124

Sitorus J, Sofyan A, Abdulfatah MY (2006) Developing a fractional flow curve from historic production to predict performance of new horizontal wells, Bekasap Field, Indonesia. In: Paper SPE 101144 presented at Asia Pacific oil \& gas conference and exhibition, Adelaide, Australia, 11-13 September. doi:10.2118/ 101144-MS

Tang H, Luo MG (2003) The study of the water-cut of the development wells during the different period. J Southwest Pet Inst 25(3):30-32

Wang M, Sun JM, Lai FQ (2010) A new water saturation model for non-net pay in low closure reservoir. J Southwest Pet Univ (Science \& Technology Edition) 32(1):27-32

Xu HB, Li XF, Shi DP (2010) An analytical method for calculating water cut of producers in injection-production pattern. Acta Petrolei Sinica 31(3):471-474

Yang XJ (2008) Prediction of the variation of single-well water-cut using Usher model. J Xi an Shiyou Univ (Natural Science Edition) 23(3):50-51

Yang B, Kuang LC, Sun ZC (2006) Prediction of reservoir water saturation by genetic programming. J Chengdu Univ Technol (Science \& Technology Edition) 33(2):209-213

Yao HS, Xiang KL, Li ZP (1999) Analytical forecasting for water saturation of reservoirs. Syst Eng Theory Pract 3:137-142

Zhao GZ, Meng SG, Jiang XC (2004) Neural network method for prediction of water cut in polymer flooding. Acta Petrolei Sinica 25(1):70-73

Zhao H, Li Y, Cao L (2010) A quantitative mathematic model for polymer flooding water-cut variation. Pet Explor Dev 37(6) :737-742 